\title{
Distribution and antibiotic pattern of non fermenting gram negative bacilli isolation in a tertiary care hospital
}

\author{
Mowna Karthik ${ }^{1, *}$, Dinesh Kaliyamoorthy² \\ ${ }^{1}$ Lab Specialist, ${ }^{2}$ Assistant Professor, Dept. of Microbiology, Dr. Sulaiman al habib hospital, Riyadh Ksa, Saudi Arabia, India \\ *Corresponding Author: \\ Email: drmowna@gmail.com
}

\begin{abstract}
Introduction: Non Fermenting Gram Negative Bacilli (NFGNB) are group of organisms commonly present in hospital environment spreading through fomites. They are said to be isolated in $15 \%$ of all the isolates in infection. Owing to increase in drug resistance, there is a growing need to understand the pattern of presentation. This study was done to evaluate the distribution and pattern of presentation of NFGNB in isolates in hospital setting.

Materials and Methods: This cross sectional study was carried out on 415 specimens analyzed in the laboratory of a tertiary care hospital for a period of one year and five months. All the clinical samples received were processed under standard protocol of inoculation and incubation. The blood culture bottles were placed in Bac T/ Alert $3 \mathrm{D}$ and the positive culture bottle were processed by Grams stain and in routine bacteriological media for inoculation and incubated. The Non fermenting Gram negative organisms isolated were subjected for identification and antibiotic susceptibility profile by VITEK 2 and manual methods.

Results: Majority of the isolates was identified as Pseudomonas spp (67.5\%) followed by Acinetobacter spp (26.2\%). Maximum specimens examined were urine samples (34.9\%) followed by pus (25.3\%). Overall, Amikacin, Ceftazidine and Cefipime were found to be the most sensitive antibiotic for NFGNB.

Conclusion: There is a growing need to judicious use of antibiotics in NFGNB infections in order to prevent further antibiotic resistance thereby reducing health care costs and challenges in infectious disease management.
\end{abstract}

Keywords: Acinetobacter spp, Drug resistance, Gram negative infections, Non fermenting bacteria, Pseudomonas spp.

\section{Introduction}

Non Fermenting Gram Negative Bacilli (NFGNB) are non sporing bacteria which is devoid of glucose in storage or function. For many years, NFGNB was considered as contaminants or commensals and were given less importance in infectious diseases management. There has been a recent trend showing an increased incidence of these bacilli with the evolving immunocompromised states and drug resistant infections. Recent studies have demonstrated a prevalence of $15 \%$ in all the bacterial isolates of clinical samples. ${ }^{1}$

This scenario is also greatly influenced by the prescription practices and antibiotic overuse and misuse. There is a rampant emergence of multidrug resistant pattern and inherent resistance to many antibiotics observed with these bacilli. Moreover, in immunocompromised states such as diabetes mellitus, etc. NFGNB other than Psuedomonas spp and Acinetobacter spp are also implicated in the disease causation. $^{2}$ As a result of growing incidence of such bacilli, there is a need to observe the pattern of occurrence in samples isolated from the hospital admissions.

NFGNB are common bacilli easily found in soil and water. In a hospital set up, they are often isolated from ventilator machine humidifiers, mattresses, tubings. ${ }^{3}$ These organisms are capable of spreading through fomites and therefore may also be isolated from skin of healthcare workers. ${ }^{4}$
There is an imminent need to evaluate the pattern of incidence of NFGNB in health care industry. The increasing emergence of drug resistance and the increasing morbidity and mortality observed among ventilator patients have posed critical challenges to the health care delivery systems, in terms of reducing the hospital stay and health care costs.

\section{Objectives}

This study was carried out

1. To estimate the prevalence of Non Fermenting Gram Negative Bacilli in isolates in the tertiary care hospital.

2. To analyze the antibiotic resistance pattern in the isolates of NFGN bacteria.

\section{Methodology \\ Study setting and study samples}

This cross sectional study was carried out in the Department of Microbiology in a tertiary care hospital for a period of one year and five months between January 2017 and May 2018. All the microbiological samples received during this period were included in the study. Samples which were repeated from the same patient and same site of collection were excluded.

\section{Data collection}

All the clinical samples received for Bacteriological culture in Microbiology section of the laboratory were processed and analyzed. The blood culture bottles were 
placed in Bac T/ Alert $3 \mathrm{D}$ and the positive culture bottle were processed by Grams stain and in routine bacteriological media for inoculation and incubated. All other samples were inoculated in the respective media and methods as per standard guidelines and incubated. The Non fermenting Gram negative organisms isolated from all the clinical samples were subjected for determining the identification and antibiotic susceptibility profile by VITEK 2 and manual methods.

\section{Data analysis}

Data was entered and analyzed using Microsoft Excel spreadsheet 2010. The prevalence of NFGNB was expressed as percentages. The antibiotic susceptibility profile was expressed in percentages.

\section{Results}

A total of 415 samples were analyzed in this study. The background characteristics of the study samples are given in Table 1. Majority of the isolates was identified as Pseudomonas spp $(67.5 \%)$ followed by Acinetobacter spp (26.2\%). Maximum specimens examined were urine samples (34.9\%) followed by pus (25.3\%)

The distribution of Pseudomonas aeroginosa in the specimens is given in table 2. It was observed that
Pseudomonas bacilli was found to be highest in urine samples (37.5\%) followed by pus samples (23.2\%)

The distribution of Acinetobacter spp among the study samples is given in table 3 . The bacteria was found to be highest in pus samples (29.4\%), followed by urine samples $(28.4 \%)$.

The distribution of Stenotrophomonas maltophilia, Sphingomonas sp, Burkholderia and Achromobacter among the study samples is given in table 4, 5, 6 and 7 respectively. Stenotrophomonas maltophilia, Sphingomonas sp were found to be highly prevalent in pus samples $(45.5 \%)$ and $(50 \%)$ respectively, while Burkholderia and Achromobacter were found to be highly prevalent in respiratory secretions, namely tracheal aspirations and sputum specimens.

The antibiotic susceptibility profile of the NFGNB in the study samples is given in figure 1. Pseudomonas OP was found to be highly and equally susceptible to Amikacin, Ceftazidime and Cefipime. Similar results were obtained with Acinetobacter OP bacilli, which in addition to these drugs, was also found to be susceptible to Meropenam. Overall, Amikacin, Ceftazidime and Cefipime were found to be the most sensitive antibiotic for NFGNB.

Table 1: Background Characteristics among the study samples

\begin{tabular}{|l|l|c|c|}
\hline S. No & Background characteristic & $\begin{array}{c}\text { Frequency } \\
(\mathbf{n = 4 1 5})\end{array}$ & $\begin{array}{c}\text { Percentage } \\
(\mathbf{\%})\end{array}$ \\
\hline \multirow{4}{*}{1} & Distribution of Bacteria & \multicolumn{3}{|c|}{} \\
\cline { 2 - 4 } & Pseudomonas aeruginosa & 280 & 67.5 \\
\cline { 2 - 4 } & Acinetobacter sp & 109 & 26.2 \\
\cline { 2 - 4 } & Stenotrophomonas maltophilia & 11 & 2.8 \\
\cline { 2 - 4 } & Sphingomonas sp & 6 & 1.4 \\
\cline { 2 - 4 } & Burkholderia & 3 & 0.7 \\
\cline { 2 - 4 } & Achromobacter & 6 & 1.4 \\
\hline \multirow{4}{*}{2} & Distribution of samples & 105 & 25.3 \\
\cline { 2 - 4 } & Pus & 141 & 34.7 \\
\cline { 2 - 4 } & Urine & 19 & 4.4 \\
\cline { 2 - 4 } & Blood & 34 & 8.2 \\
\cline { 2 - 4 } & Tracheal aspirations & 13 & 3.1 \\
\cline { 2 - 4 } & Ear discharge & 92 & 22.1 \\
\cline { 2 - 4 } & Sputum & 1 & 0.2 \\
\cline { 2 - 4 } & Bile & 7 & 1.3 \\
\cline { 2 - 4 } & Pleural fluid & 3 & 0.7 \\
\cline { 2 - 4 } & Conjunctival secretions & \multicolumn{2}{|c}{} \\
\hline
\end{tabular}

Table 2: Pseudomonas aeruginosa among different specimens

\begin{tabular}{|c|l|c|c|}
\hline S. No & \multicolumn{1}{|c|}{ Characteristics } & $\begin{array}{c}\text { Frequency } \\
(\mathbf{n = 2 8 0})\end{array}$ & $\begin{array}{c}\text { Percentage } \\
(\mathbf{\%})\end{array}$ \\
\hline 1 & Pus & 65 & 23.3 \\
\hline 2 & Urine & 105 & 37.6 \\
\hline 3 & Blood & 15 & 5.4 \\
\hline 4 & Tracheal aspirations & 17 & 6.0 \\
\hline 5 & Ear discharge & 11 & 3.9 \\
\hline 6 & Sputum & 61 & 21.8 \\
\hline 7 & Bile & 0 & 0 \\
\hline
\end{tabular}




\begin{tabular}{|l|l|l|l|}
\hline 8 & Pleural fluid & 3 & 1.0 \\
\hline 9 & Conjunctival secretions & 3 & 1.0 \\
\hline
\end{tabular}

Table 3: Acinetobacter sp among different specimens

\begin{tabular}{|c|l|c|c|}
\hline S. No & \multicolumn{1}{|c|}{ Characteristics } & $\begin{array}{c}\text { Frequency } \\
(\mathbf{n = 1 0 9})\end{array}$ & $\begin{array}{c}\text { Percentage } \\
(\mathbf{\%})\end{array}$ \\
\hline 1 & Pus & 32 & 29.4 \\
\hline 2 & Urine & 31 & 28.4 \\
\hline 3 & Blood & 3 & 2.8 \\
\hline 4 & Tracheal aspirations & 12 & 11.0 \\
\hline 5 & Ear discharge & 1 & 0.9 \\
\hline 6 & Sputum & 25 & 22.9 \\
\hline 7 & Bile & 1 & 0.9 \\
\hline 8 & Pleural fluid & 4 & 3.7 \\
\hline 9 & Conjunctival secretions & 0 & 0 \\
\hline
\end{tabular}

Table 4: Stenotrophonomonas maltophilia among different specimens

\begin{tabular}{|c|l|c|c|}
\hline S. No & \multicolumn{1}{|c|}{ Characteristics } & $\begin{array}{c}\text { Frequency } \\
(\mathbf{n = 1 1})\end{array}$ & $\begin{array}{c}\text { Percentage } \\
(\mathbf{\%})\end{array}$ \\
\hline 1 & Pus & 5 & 45.4 \\
\hline 2 & Urine & 1 & 9.9 \\
\hline 3 & Blood & 0 & 0 \\
\hline 4 & Tracheal aspirations & 3 & 27.1 \\
\hline 5 & Ear discharge & 0 & 0 \\
\hline 6 & Sputum & 2 & 18.6 \\
\hline 7 & Bile & 0 & 0 \\
\hline 8 & Pleural fluid & 0 & 0 \\
\hline 9 & Conjunctival secretions & 0 & 0 \\
\hline
\end{tabular}

Table 5: Sphingomonas sp among different specimens

\begin{tabular}{|c|l|c|c|}
\hline S. No & \multicolumn{1}{|c|}{ Characteristics } & $\begin{array}{c}\text { Frequency } \\
(\mathbf{n = 6})\end{array}$ & $\begin{array}{c}\text { Percentage } \\
(\mathbf{\%})\end{array}$ \\
\hline 1 & Pus & 3 & 50.3 \\
\hline 2 & Urine & 1 & 16.8 \\
\hline 3 & Blood & 0 & 0 \\
\hline 4 & Tracheal aspirations & 0 & 0 \\
\hline 5 & Ear discharge & 1 & 16.8 \\
\hline 6 & Sputum & 1 & 16.8 \\
\hline 7 & Bile & 0 & 0 \\
\hline 8 & Pleural fluid & 0 & 0 \\
\hline 9 & Conjunctival secretions & 0 & 0 \\
\hline
\end{tabular}

Table 6: Burkholderia among different spicemens

\begin{tabular}{|c|l|c|c|}
\hline S. No & \multicolumn{1}{|c|}{ Characteristics } & $\begin{array}{c}\text { Frequency } \\
(\mathbf{n = 3})\end{array}$ & $\begin{array}{c}\text { Percentage } \\
(\mathbf{\%})\end{array}$ \\
\hline 1 & Pus & 0 & 0 \\
\hline 2 & Urine & 1 & 33.3 \\
\hline 3 & Blood & 0 & 0 \\
\hline 4 & Tracheal aspirations & 2 & 66.7 \\
\hline 5 & Ear discharge & 0 & 0 \\
\hline 6 & Sputum & 0 & 0 \\
\hline 7 & Bile & 0 & 0 \\
\hline 8 & Pleural fluid & 0 & 0 \\
\hline 9 & Conjunctival secretions & 0 & 0 \\
\hline
\end{tabular}


Table 7: Achromobacter among different spicemens

\begin{tabular}{|c|l|c|c|}
\hline S. No & \multicolumn{1}{|c|}{ Characteristics } & $\begin{array}{c}\text { Frequency } \\
(\mathbf{n = 6})\end{array}$ & $\begin{array}{c}\text { Percentage } \\
(\mathbf{\%})\end{array}$ \\
\hline 1 & Pus & 0 & 0 \\
\hline 2 & Urine & 2 & 33.3 \\
\hline 3 & Blood & 1 & 16.7 \\
\hline 4 & Tracheal aspirations & 0 & 0 \\
\hline 5 & Ear discharge & 0 & 0 \\
\hline 6 & Sputum & 3 & 50 \\
\hline 7 & Bile & 0 & 0 \\
\hline 8 & Pleural fluid & 0 & 0 \\
\hline 9 & Conjunctival secretions & 0 & 0 \\
\hline
\end{tabular}

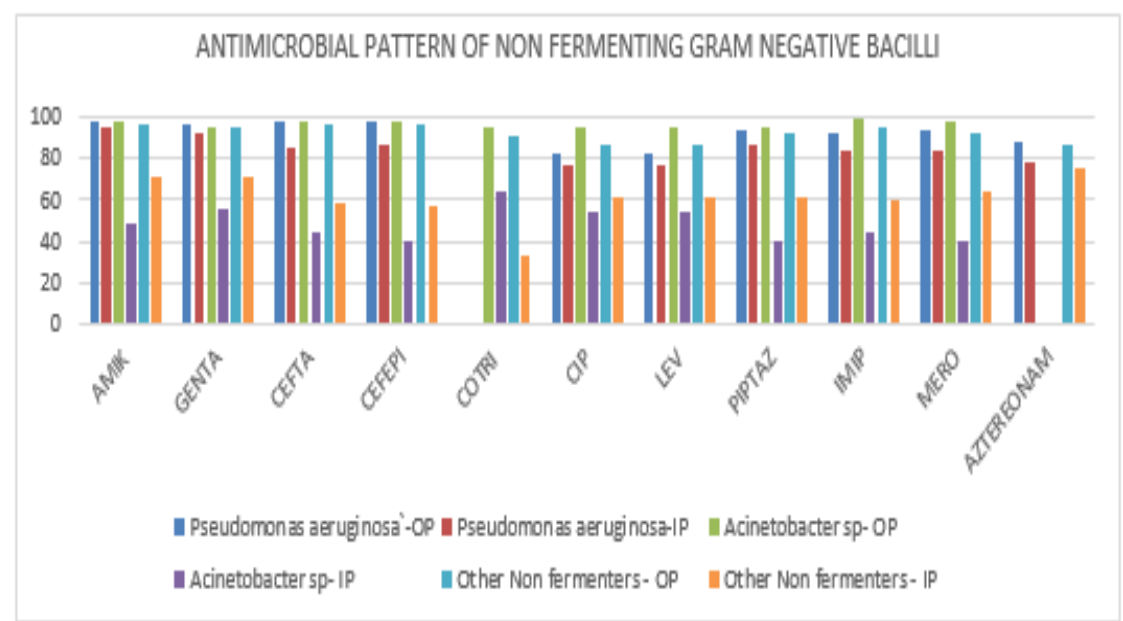

Fig. 1: Antimicrobial Sensitivity pattern of non fermenting gram negative bacilli

\section{Discussion}

The importance of evaluating the pattern of occurrence of NFGN bacteria has increased in the recent times owing to increase in drug resistance and increased incidence of ventilator patients. The emergence of drug resistance has been instrumental in initiating the study on the species, source of infection and molecular mechanism in NFGNB. Moreover, the use of VITEK 2 has largely simplified the process of identification, thereby making it user friendly. ${ }^{5}$

The prevalence of NFGNB in a study done by Chawla $\mathrm{K}$ in respiratory samples was $16.4 \% .^{6}$ In another study done by Malini et al, the prevalence was found to be $6.8 \% .^{7}$ Our study demonstrated a high prevalence of Pseudomonas spp in the specimens analyzed. In a study done by Mo Q et al, Psuedomonas was the highest documented NFGN bacilli. ${ }^{8}$ Overall, various published studies in India quote a prevalence ranging from $2.18 \%$ to $45.9 \%{ }^{9}$

The organisms other than pseudomonas which are often identified include Acinetobacter, Burkhoderia and Stenotrophomonas which are predominantly isolated from the pus specimens and respiratory aspirations. Among these, Acinetobacters have emerged as the most successful pathogens by their ability to survive in hospital environment in both dry and moist surfaces for a long period of time. These bacteria acidify most carbohydrates and demonstrate rapid production of acid from $1 \%$ and $10 \%$ lactose. They are a strong group of multidrug resistance NFGN and achieving antibiotic susceptibility to common drugs continues to be a challenge. ${ }^{10}$

Our study demonstrated high susceptibility to Amikacin, Ceftazidime and Cefipime. A study done by Kesli $\mathrm{R}$ also reported similar findings, with high susceptibility to Amikacin, followed by gentamycin. ${ }^{11}$ Antibiotic resistance is a key phenomenon to be explored in the case of NFGNB. Inappropriate use of antibiotics has complicated the entire scenario of infectious disease management, further worsening the disease burden and health care costs. The outer memberane of NFGN bacteria, which is composed of lipid A and polysaccharides are completely destroyed, exposing the endotoxin, which, in turn is associated with antibiotic resistance. Moreover, long term and inappropriate use of these antibiotics interferes with the permeability of the bacterial cell membranes, resulting in increased intracellular lactamase levels. Further, the antibiotic resistance is likely to be associated with intracellular CTX-M ESBL expression which needs to be further explored in terms of its implications. ${ }^{8}$ 


\section{Conclusion}

Our study has demonstrated that Pseudomonas and Acinetobacter spp are the most common organisms in the NFGNB group to be found in tertiary care centres. Considering the increase in the burden and morbidity associated with ventilator use, the risk of multi drug resistance in NFGN is bound to increase in the times to come. Moreover, inappropriate use of antibiotics has increases resistance to several first line drugs, thereby forcing the health care providers to choose third generation drugs, which have been currently found to be sensitive to these bacteria.

\section{Limitations}

Our study did not explore the underlying pathology or the status of hospitalization among the study participants. Moreover, since it is a descriptive study, we did not evaluate the outcome of these infections, therefore there is a wide scope to assess the impact of the NFGNB infections, which, in future, will help in health care planning and preventive strategies.

Funding: No funding sources.

Conflict of interest: None declared.

\section{References}

1. Gokhale S, Metgud SC. Characterization and antibiotic sensitivity pattern of nonfermenting Gram negative bacilli from various clinical samples in a tertiary care hospital. Belgaum J Pharm Biomed Sci 2012;17:1-5.

2. Fass RJ, Barnishan J, Solomon MC, Ayers LW. In vitro activities of quinolones, beta-lactams, tobramycin, and trimethoprim-sulfamethoxazole against nonfermentative gram-negative bacilli. Antimicrob Agents Chemother 1996 Jun; 40(6):1412-8.

3. Mellmann A, Bimet F, Bizet C, Borovskaya AD, Drake RR, Eigner U, et al. High interlaboratory reproducibility of matrix-assisted laser desorption ionization-time of flight mass spectrometry-based species identification of nonfermenting bacteria. J Clin Microbiol 2009;47(11):3732-34.
4. McGowan JE Jr Resistance in nonfermenting gramnegative bacteria: multidrug resistance to the maximum. Am J Med 2006;119(6 Suppl 1):S29-36; discussion S6270.

5. Funke G, Funke-Kissling P Evaluation of the new VITEK 2 card for identification of clinically relevant gramnegative rods. J Clin Microbiol 2004;42(9):4067-71.

6. Chawla K, Vishwanath S, Munim FC. Non fermenting Gram negative Bacilli other than Pseudomonas aeruginosa and Acinetobacter Spp causing Respiratory Tract infections in a tertiary care center. J Glob Infect Dis 2013;5(4):144-46.

7. Malini A, Deepa E, Gokul B, Prasad S. Nonfermenting gram-negative bacilli infections in a tertiary care hospital in kolar, karnataka. J Lab Physicians 2009;1(2):62-6.

8. Mo Q, Lou T, Wang L, Zhong H, Dong Y, Ma D, et al. Molecular mechanism of drug resistance of non fermentative Gram negative bacteria in hospitals. Int $J$ Clin Exp Pathol 2016;9(3):3586-92.

9. Deepak J, Rajat P, Shamanth AS, Munesh S, Vikrant N, Neelam S. Prevalence of Non fermenting gram negative bacilli and their in vitro susceptibility pattern in a tertiary care hospital of Uttarakhand: A study from foot hills of Himalayas. SJHS 2013;2:108-12.

10. Aprameya IV. Non fermenting gram negative bacilli (NFGNB) other than Pseudomonas. J Acad Clin Microbiol 2013;15:59-61.

11. Kesli R. Antibiotic Resistance profiles of non fermentative gram negative rods:Acinetobacter spp, Pseudomonas spp, and Stenetrophomonas spp in Kocatepe University Hospital. In: Proceedings of the $3^{\text {rd }}$ World Congress Expo on Applied Microbiology. 2016 November 7-9; Dubai. Available from https://www.omicsonline.org/abstract/antibioticresistance-profiles-of-non-fermentative-gram-negativerods-acinetoabacter-spp-pseudomonas-spp-andstenetrophomonas-spp-in-kocatepe-university-hospital2012-2015.

How to cite this article: Karthik M. Kaliyamoorthy D. Distribution and antibiotic pattern of non fermenting gram negative bacilli isolation in a tertiary care hospital. Int J Med Microbiol Trop Dis 2018;4(4):206-10. 